Acta Bot. Croat. $72(1), 13-22,2013$

\title{
Comparative study of in vitro, ex vitro and in vivo grown plants of Arnica montana - polyphenols and free radical scavenging activity
}

\author{
Milena Nikolova $^{1 *}$, Mariya Petrova ${ }^{2}$, Ely Zayova $^{2}$, Antonina VitKova $^{1}$, \\ LJUBA EvSTATIEVA ${ }^{1}$ \\ ${ }^{1}$ Institute of Biodiversity and Ecosystem Research, Acad. G. Bonchev 23, 1113 Sofia, \\ Bulgaria \\ ${ }^{2}$ Institute of Plant Physiology and Genetics, 21 G. Bonchev Street, 1113 Sofia, Bulgaria
}

\begin{abstract}
Arnica montana L. is an endangered species rich in sesquiterpene lactones, phenolic acids and flavonoids with high pharmaceutical value. The polyphenolic content and free radical scavenging activity of plants that had passed all stages of cultivation: micropropagation and rooting (in vitro), adaptation in greenhouse (ex vitro) and mountain conditions (in vivo) were evaluated. Four surface flavonoid aglycones [scutellarein 6-methyl ether (hispidulin), scutellarein 6,4'-dimethyl ether (pectolinarigenin), 6-OH luteolin 6-methyl ether and kempferol-6-methyl ether] were detected in the acetone exudates of the studied samples by means of thin layer chromatography. No differences in the accumulation of surface flavonoids were found among the tested leaf extracts of in vitro, ex vitro and in vivo samples. However, the extracts from the flowers were richer in surface flavonoids than extracts from the leaves. The methanol extracts of the samples from ex vitro and in vivo grown A. montana plants had significantly higher radical scavenging activity and polyphenolic content than the extracts of in vitro samples. The observed differences in the contents of these biologically active compounds were related to different growth conditions and stages of plant development. The biotechnological method of A. montana established holds promise for the future production of antioxidants.
\end{abstract}

Keywords: antioxidant, flavonoid, phenol, Arnica montana

\section{Introduction}

Arnica montana L. (Asteraceae) is a valuable perennial herb. The species contains sesquiterpene lactones (e.g. helenalin), phenolic acids (caffeic acid derivatives) and flavonoids (quercetin 3-O-glucuronic acid) with significant antiseptic, anti-inflammatory, antibacterial and antioxidant effects (WOERDENBAG et al. 1994, LYSS et al. 1997, IAUK et al.

* Corresponding author, e- mail: milena_n@bio.bas.bg

Copyright ${ }^{\circledR} 2013$ by Acta Botanica Croatica, the Faculty of Science, University of Zagreb. All rights reserved. 
2003, SANTOS et al. 2006). The plant has been used mainly as anti-inflammation drug and is applied topically for skin, bruises, rheumatic and muscle pains. The species is used as ingredient in many homeopathic remedies. Arnica montana is a rarely found in Bulgaria and has been reported to grow only on Rila mountain (ASSYOv and PETROVA 2006), however so far its distribution has not been confirmed. Therefore the development of a biotechnological method for in vitro propagation of the species and subsequently ex vitro and in vivo acclimatization is very important for its cultivation and sustainable use.

Phenolic compounds and flavonoids possess multiple biological effects including antioxidant, free radical scavenging abilities, inhibition of hydrolytic and oxidative enzymes, anti-inflammatory, anticarcinogenic, antibacterial, hypolipidemic, antimutagenic and other activities (Burda and OleszeK 2001, CAI et al. 2004, RochA-GuZMAN et al. 2007). They are also associated with the prevention and treatment of cardiovascular and cerebrovascular diseases (GAN et al. 2010). Arnica montana flavonoids are supposed to act synergistically with sesquiterpene lactones (WILLUHN 1991). They also serve as chemosystematic markers and are used to assess identity and purity of A. montana according to the European Pharmacopoeia (HÄNSEL and STICHER et al. 2007). The total polyphenol content and antioxidant activity of A. montana extracts have been reported in several publications (HAĂRMĂNESCU et al. 2008, Fraisse et al. 2011, GAWLIK-DzIKI et al. 2011, Moldovan et al. 2011). The literature survey showed that there is no information about the antioxidant activity of in vitro cultured A. montana plant material.

The purpose of this study was to evaluate the polyphenol content and antioxidant capacity of plants derived from in vitro culture and then adapted in greenhouse (ex vitro) and mountain conditions (in vivo).

\section{Material and methods}

\section{Plant material}

The origin of Arnica montana plants was Botanical Garden, Germany (AG). Six samples were analyzed: two in vitro samples: AGM (multiple plants), AGR (rooted plants); two ex vitro samples AG1: AG1_L (leaves), AG1_F (flower heads) of greenhouse plants from Sofia region $553 \mathrm{~m}$ a.s.l. and two in vivo sample AG2: AG2_L (leaves), AG2_F (flower heads) of cultivated plants from the Rhodope Mountains, Beglika.

\section{Preparation of extracts}

Acetone exudates. Air-dried (but not ground) 1g plant material was briefly (2-3 min) rinsed with acetone at room temperature to dissolve the lipophilic components accumulated on the surface. The obtained acetone filtrate was then dried using a rotary-evaporator to give a crude extract which was suspended in $\mathrm{MeOH}$ and then subjected on TLC.

Methanol extracts. Dry, ground plant material (1 g) was extracted with 80\% (3 x 30 $\mathrm{mL}$ ) methanol by classic maceration for $24 \mathrm{~h}$. After evaporation of the solvent the crude extract was subjected to subsequent analysis.

Biotechnological tools: The in vitro propagation protocol of A. montana plants consisted of four stages: 1) an initial stage - obtaining seedlings on basal MS medium (Murashige and SKOOG 1962) with $40 \mathrm{mg} \mathrm{L}^{-1}$ gibberellic acid; 2) a propagation stage - 
shoot formation on MS medium supplemented with $1 \mathrm{mg} \mathrm{L}^{-1}$ 6-benzylaminopurine and 0.1 $\mathrm{mg} \mathrm{L}^{-1}$ indole-3-acetic acid; 3 ) rooting stage - shoot rooting on half strength MS medium containing $0.5 \mathrm{mg} \mathrm{L}^{-1}$ indole-3-butyric acid; 4) ex vitro acclimatization of plants was carried out on a mix of peat, perlite and coconut fiber $(2: 1: 1 \mathrm{v} / \mathrm{v} / \mathrm{v})$ for 4 weeks. Then the plants were adapted in the experimental field in the Rhodopes Mountains at an altitude of $1500 \mathrm{~m}$ a.s.l (in vivo plants).

\section{Cultural conditions}

In vitro cultures were maintained in a growth room at temperature of $22 \pm 2{ }^{\circ} \mathrm{C}$ under a $16 \mathrm{~h}$ photoperiod with light intensity of $40 \mu \mathrm{M} \mathrm{m}^{-2} \mathrm{~s}^{-1}$ provided by cool white fluorescent tubes. The micropropagated plants were cultivated in ex vitro conditions ata temperature of $24 \pm 2{ }^{\circ} \mathrm{C}$ under a $16 \mathrm{~h}$ photoperiod with a light intensity of $50 \mu \mathrm{M} \mathrm{m}^{-2} \mathrm{~s}^{-1}$ with subsequent transfer to greenhouse. Then the plants were adapted in the experimental field in the Rhodopes Mountains at an altitude of $1500 \mathrm{~m}$ a.s.l (in vivo plants).

\section{Thin layer chromatographic analysis of flavonoid aglycones}

The acetone exudates were screened for surface flavonoids by TLC analysis. Three TLC sorbents and three mobile phases were used for the analysis of the flavonoid exudates. Toluene-dioxan-acetic acid (95:25:4, v/v/v) was applied for the development of the aglycones mixture on silica gel plates Kiselgel $60 \mathrm{~F}_{254}(10 \times 20 \mathrm{~cm}, 0.2 \mathrm{~mm}$ layer). Toluene-methylethylketone-methanol (60:25:15, v/v/v) was used for DC-Alufolien Polyamid 11 $\mathrm{F}_{254}$ plates $(10 \times 20 \mathrm{~cm}, 0.15 \mathrm{~mm}$ layer $)$. Acetic acid-water $(30: 70, \mathrm{v} / \mathrm{v})$ was used for cellulose plates DC-Alufolien Cellulose $5552(10 \times 20 \mathrm{~cm}, 0.1 \mathrm{~mm}$ layer). Chromatograms were viewed under UV light before and after spraying with »Natural product reagent $\mathrm{A} \ll$, $1 \%$ solution of diphenylboric acid 2-aminoethyl ester complex in methanol. The identification of the compounds was achieved by co-chromatography with authentic markers obtained from Prof. Eckhard Wollenweber.

Determination of total phenolic content. Total phenolic content of the methanol extracts was determined by employing the methods given in the literature involving Folin-Ciocalteu reagent and gallic acid as standard (GIORGI et al. 2009, NićIFOROVIĆ et al. 2010). Plant extracts were diluted to a concentration of $1 \mathrm{mg} \mathrm{mL}^{-1}$, and aliquots of $0.5 \mathrm{~mL}$ were mixed with $2.5 \mathrm{~mL}$ of Folin-Ciocalteu reagent (previously diluted 10-fold with distilled water) and $2 \mathrm{~mL}$ of $\mathrm{Na}_{2} \mathrm{CO}_{3}(6 \%)$. After $1 \mathrm{~h}$ at room temperature, the absorbances of the samples were measured at $765 \mathrm{~nm}$ on spectrophotometer versus blank sample. Total phenols were determined as gallic acid equivalents (mg GA per $\mathrm{g}$ of extract) by the following formula:

$$
\mathrm{C}=\mathrm{c} \times \mathrm{V} / \mathrm{m}
$$

where $\mathrm{C}$ is total content of phenolic compounds, $\mathrm{mg} \mathrm{g}^{-1}$ plant extract, in GAE; $\mathrm{c}$ is the concentration of gallic acid established from the calibration curve in $\mu \mathrm{g} \mathrm{mL}^{-1} ; \mathrm{V}$ is the volume of extract in $\mathrm{mL} ; \mathrm{m}$ is the weight of pure plant methanolic extract in grams.

Determination of total flavonoid content. Total flavonoid content was determined according to MiLIAUSKASA et al. (2004), using rutin as a reference compound. One mL of plant 
extract in methanol $\left(10 \mathrm{~g} \mathrm{~L}^{-1}\right)$ was mixed with $1 \mathrm{~mL}$ aluminium trichloride in ethanol $(20 \mathrm{~g}$ $\mathrm{L}^{-1}$ ) and diluted with ethanol to $25 \mathrm{~mL}$. The absorption at $415 \mathrm{~nm}$ was read after $40 \mathrm{~min}$ at room temperature. Blank samples were prepared from $1 \mathrm{~mL}$ plant extract and 1 drop acetic acid and diluted to $25 \mathrm{~mL}$. The absorption of rutin solutions was measured under the same conditions. Standard rutin solutions were prepared from $0.05 \mathrm{~g}$ rutin. All determinations were carried out in duplicate. The amount of flavonoids in plant extracts in rutin equivalents (RE) was calculated by the following formula:

$$
\mathrm{C}=\mathrm{Ab}_{\text {sample }} \times \mathrm{m}_{\text {control }} \times 10 / \mathrm{Ab}_{\text {control }} \times \mathrm{m}_{\text {sample }}
$$

where $\mathrm{C}$ is flavonoid content $\left(\mathrm{mg} \mathrm{g}^{-1}\right.$ plant extract) in $\mathrm{RE}$; $\mathrm{Ab}_{\text {sample }}$ is the absorption of plant extract solution; $\mathrm{Ab}_{\text {control }}$ is the absorption of standard rutin solution; $\mathrm{m}_{\text {sample }}$ is the weight of plant extract in grams; $\mathrm{m}_{\text {control }}$ is the weight of rutin in the solution in grams.

DPPH radical scavenging activity. The effect of methanolic extracts on DPPH radical was estimated according to CHOI et al. (2002) and STANOJEVIĆ et al. (2009). Different concentrations of plant extract $(10,20,50,100$ and $200 \mu \mathrm{g} / \mathrm{mL})$, in methanol were added at an equal volume $(2.5 \mathrm{~mL})$ to methanol solution of DPPH $(0.3 \mathrm{mM}, 1 \mathrm{~mL})$. After $30 \mathrm{~min}$ at room temperature, the Ab values were measured at $517 \mathrm{~nm}$ on a spectrophotometer (Jenway 6320D) and converted into the percentage antioxidant activity using the following equation:

$$
\text { DPPH antiradical scavenging capacity }(\%)=\left[1-\left(\mathrm{Ab}_{\text {sample }}-\mathrm{Ab}_{\text {blank }}\right) / \mathrm{Ab}_{\text {control }}\right] \times 100
$$

Methanol $(1.0 \mathrm{~mL})$ plus plant extract solution $(2.5 \mathrm{~mL})$ was used as a blank, while $\mathrm{DPPH}$ solution plus methanol was used as a control. The $\mathrm{IC}_{50}$ values were calculated by sigmoid non-linear regression model using plots, where the abscissa represented the concentration of tested plant extracts and the ordinate the average percent of scavenging capacity (Software Prizm 3.00). $\mathrm{IC}_{50}$ values denote the concentration of sample required to scavenge $50 \%$ of DPPH radical.

\section{Statistical analysis}

Statistical analysis was carried out using excel. All experiments were performed in triplicate. Results were presented as a value \pm standard deviation (SD). Significant levels were defined at $\mathrm{p}<0.05$ as analyzed by t-test.

\section{Results}

\section{Surface flavonoid aglycones}

Four surface flavonoid aglycones were detected in the acetone exudates of the studied samples (Fig. 1): scutellarein 6-methyl ether (hispidulin) (1), scutellarein 6,4'-dimethyl ether (pectolinarigenin) (2), 6-OH luteolin 6-methyl ether (3) and kempferol-6-methyl ether (4). Three of detected flavonoid structures belong to the flavone class of flavonoids and one belongs to the flavonol class. Thin layer chromatographic data $-\mathrm{R}_{\mathrm{F}}$ (rate of flow) and color of detected flavonoid aglycones are presented in table 1. The flavonoid aglycones (1) and (2) were the main flavonoids in all studied exudates. The flavonoid aglycones (3) and (4) 


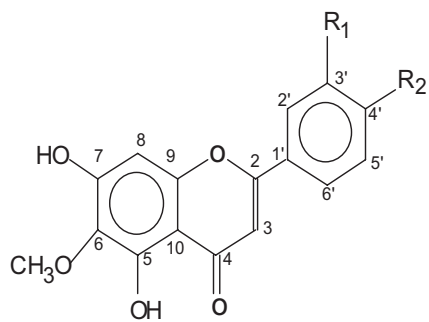

$(1,2,3)$

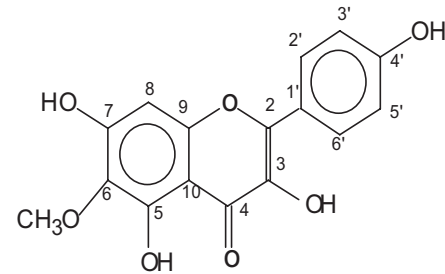

(4)

(1) $\mathrm{R}_{1}=\mathrm{H} ; \mathrm{R}_{2}=\mathrm{OH}$ scutellarein 6-methyl ether (hispidulin)

(2) $\mathrm{R}_{1}=\mathrm{H} ; \mathrm{R}_{2}=\mathrm{OCH}_{3}$ scutellarein 6,4'-dimethyl ether (pectolinarigenin)

(3) $\mathrm{R}_{1}=\mathrm{OH} ; \mathrm{R}_{2}=\mathrm{OH} 6-\mathrm{OH}$ luteolin 6-methyl ether (3)

(4) kempferol-6-methyl ether

Fig. 1. Structures of the identified flavonoid aglycones $1-4$.

Tab. 1. Thin layer chromatographic data on detected flavonoid aglycones in the studied samples of Arnica Montana

\begin{tabular}{|c|c|c|c|}
\hline \multirow{2}{*}{ Flavonoid aglycones } & \multicolumn{3}{|c|}{ Thin layer chromatographic data $-\mathrm{R}_{\mathrm{F}}$ (rate of flow) and color } \\
\hline & $\mathrm{S}_{1}$ & $\mathrm{~S}_{2}$ & $\mathrm{~S}_{3}$ \\
\hline $\begin{array}{l}\text { Scutellarein 6,4'-dimethyl } \\
\text { ether (pectolinarigenin) }\end{array}$ & $\begin{array}{l}0.52 \\
\text { (brown/ brown) }\end{array}$ & $\begin{array}{l}0.57 \\
\text { (brown/ brown) }\end{array}$ & $\begin{array}{l}0.67 \\
\text { (brown/ brown) }\end{array}$ \\
\hline $\begin{array}{l}\text { Scutellarein 6-methyl } \\
\text { ether (hispidulin) }\end{array}$ & $\begin{array}{l}0.33 \\
\text { (brown/ brown) }\end{array}$ & $\begin{array}{l}0.21 \\
\text { (brown / } \\
\text { brownish-yellow) }\end{array}$ & $\begin{array}{l}0.52 \\
\text { (brown/ brown) }\end{array}$ \\
\hline $\begin{array}{l}\text { Kempferol-3-methyl } \\
\text { ether }\end{array}$ & $\begin{array}{l}0.39 \\
\text { (brown / } \\
\text { brownish-yellow) }\end{array}$ & $\begin{array}{l}0.15 \\
\text { (brownish-yellow / } \\
\text { yellow) }\end{array}$ & $\begin{array}{l}0.28 \\
\text { (brownish-yellow / } \\
\text { yellow) }\end{array}$ \\
\hline $\begin{array}{l}\text { 6-OH luteolin } \\
\text { 6-methyl ether }\end{array}$ & $\begin{array}{l}0.16 \\
\text { (brown / orange) }\end{array}$ & $\begin{array}{l}0.06 \\
\text { (brown / yellow) }\end{array}$ & $\begin{array}{l}0.21 \\
\text { (brown / Light orange) }\end{array}$ \\
\hline
\end{tabular}

$S_{1}-$ sorbent=silicagel, eluent=toluene:dioxan:acetic acid (90:25:4); $S_{2}-$ sorbent $=$ polyamid, eluent $=$ toluene:methylethylketone:methanol (60:25:15); $S_{3}-$ sorbent - cellulose, eluent $=30 \%$ acetic acid

were detected in trace amounts in the leaf exudates while in the flower exudates they were present in high quantities. Differences among the leaf exudates of studied samples were not observed.

\section{Total phenolic content}

The results of total phenolic content determination in the methanol extracts of studied samples, evaluated using Folin - Ciocalteu method, are presented in table 2. The content of phenols in extracts of in vitro samples AGM and AGR expressed as gallic acid equivalents (GAE) was 23.65 to $24.78 \mathrm{mg} \mathrm{g}^{-1}$ of dry extract, respectively. There were no significant differences in content of total phenols $(p>0.05)$ among the methanol extracts of in vitro 
Tab. 2. Polyphenol content and free radical scavenging activity of samples of in vitro, ex vitro and in vivo grown Arnica montana plants

\begin{tabular}{llccc}
\hline Sample & Plant part & $\begin{array}{c}\text { Total phenols* } \\
\text { mg GAE/g extract }\end{array}$ & $\begin{array}{c}\text { Total flavonoids* } \\
(\mathrm{mg} \text { RE/g extract })\end{array}$ & $\begin{array}{c}\text { DPPH scavenging } \\
\text { activity } \\
\text { IC }_{50}(\mu \mathrm{g} / \mathrm{mL})\end{array}$ \\
\hline AGM in vitro & Leaves & $23.65 \pm 1.6^{\mathrm{a}}$ & $1.48 \pm 0.8^{\mathrm{d}}$ & $>200^{\mathrm{k}}$ \\
AGR in vitro & Leaves & $24.78 \pm 1.1^{\mathrm{a}}$ & $1.49 \pm 0.7^{\mathrm{d}}$ & $>200^{\mathrm{k}}$ \\
AG1_L ex vitro & Leaves & $38.13 \pm 3.5^{\mathrm{b}}$ & $4.20 \pm 1.4^{\mathrm{f}}$ & $64.01 \pm 5,51^{\mathrm{h}}$ \\
AG1_F ex vitro & Flower heads & $36.41 \pm 5.9^{\mathrm{b}}$ & $9.21 \pm 1.1^{\mathrm{e}}$ & $85.73 \pm 8,11^{\mathrm{j}}$ \\
AG2_Lin vivo & Leaves & $57.80 \pm 4.2^{\mathrm{c}}$ & $4.54 \pm 1.6^{\mathrm{f}}$ & $33.79 \pm 6,32^{\mathrm{g}}$ \\
AG2_F in vivo & Flower heads & $51.25 \pm 2.6^{\mathrm{c}}$ & $9.5 \pm 2.7^{\mathrm{e}}$ & $60.22 \pm 7,51^{\mathrm{h}}$ \\
\hline
\end{tabular}

AGM - in vitro sample multiple stage; AGR - in vitro sample, plant rooting stage; AG1_L - ex vitro grown plants, leaves, AG1_F - ex vitro grown plants, flower heads; AG2_L - in vivo grown plants, leaves; AG2_F - in vivo grown plants, flower heads; GAE- gallic acid equivalents; RE - rutin equivalents. * values represent mean $\pm \mathrm{SD}, \mathrm{n}=3$. Values with the same letter are not significantly different, $\mathrm{p} \geq$ 0.05

samples. The leaf extracts of ex vitro and in vivo (AG1 L and AG2 L) developing plants contain higher levels of phenols compared to extracts of in vitro samples, respectively 38.13 and $57.80 \mathrm{mg} \mathrm{g}^{-1}$ of dry extract. The extracts from flower heads of the same samples (AG1 F and AG2 F) contained phenols of respectively 36.41 and $51.25 \mathrm{mg} \mathrm{g}^{-1}$ of dry extract. The extracts of in vivo (AG2 L and AG2 F) samples contain higher phenols than extracts of ex vitro samples (AG1 L and AG1 F). The marked differences were statistically significant $(\mathrm{p}<$ 0.05). There were no significant differences in the phenolic content $(p>0.05)$, between the extracts of flower heads and leaves of a separate samples.

\section{Total flavonoid content}

Flavonoid contents is expressed as rutin equivalents: mg RE per g of dry extract. The amount of flavonoids was the lowest in the leaf extracts from in vitro grown plants AGM and AGR - 1.48 and $1.49 \mathrm{mg} \mathrm{g}^{-1}$ (Tab. 2). No differences in the content of total flavonoids among leaf extracts from ex vitro and in vivo grown plants (AG1 L and AG2 L) were observed -4.20 and $4.54 \mathrm{mg} \mathrm{g}^{-1}$ of dry extract, respectively. However, a significant difference $(\mathrm{p}<0.05)$ was found in the content of flavonoids between extracts of leaves and flowers of a sample. The extracts of flower heads of ex vitro and in vivo grown plants (AG1 F and AG2 F) contain flavonoids of respectively 9.21 and $9.50 \mathrm{mg} \mathrm{g}^{-1}$ of dry extract.

\section{DPPH free-radical scavenging activity}

The degree of discoloration of violet colour of DPPH., as it gets reduced, indicated the radical scavenging potential of the antioxidant. Results of the DPPH scavenging activity of studied samples, expressed as $\mathrm{IC}_{50}$ value that represent the concentration of the sample required to scavenge $50 \%$ of DPPH radicals, are given in table 2 .

It was found that the leaf extracts of ex vitro and in vivo samples had the strongest radical scavenging activity, respectively $\mathrm{IC}_{50}=64.01$ and $33.79 \mu \mathrm{g} \mathrm{mL}{ }^{-1}$. The extracts of in 
vitro samples showed low activity and their $\mathrm{IC}_{50}$ values were above $200 \mu \mathrm{g} \mathrm{mL}^{-1}$. The extracts of flower heads of ex vitro and in vivo samples showed slightly lower activity than the corresponding leaf extracts $\mathrm{IC}_{50}=85.73$ and $60.22 \mu \mathrm{g} \mathrm{mL}^{-1}$ respectively.

\section{Discussion}

The commercial importance of polyphenols has led to attempts to develop alternative systems for their production. The advantage of using the tissue and organ cultures is more stable production of secondary metabolites than cultures of undifferentiated cells, such as cells in callus or suspension culture (RAMACHANDRA RAO and RAVISHANKAR 2002). In the present study surface flavonoids, total phenols and flavonoids as well as the antioxidant potential of extracts from in vitro, ex vitro and in vivo grown plants of Arnica montana were analyzed. It was found that there was no difference in the synthesis of surface flavonoids among in vitro, ex vitro and in vivo grown plants. Differences were observed in the composition of surface flavonoids between the exudates of leaves and flower heads. The exudates of flower heads contained a high quantity of the flavonoids 6-OH luteolin 6-methyl ether and kempferol-6-methyl ether. This is in accordance with reports of other authors for differences in surface flavonoid composition in different plant organs (WILLIAMS et al. 1999).

The results of quantitative analysis showed that the total content of phenols and flavonoids in the extracts of in vitro cultures were lower than in the extracts of ex vitro and in vivo grown plants. The differences in the content of these secondary metabolites might be due to the different growth conditions and stages of plant development. The lower level of phenols in extracts of in vitro samples compared to extracts of field grown plants has been already reported (STANLY et al. 2001, RAMES et al. 2009, PARSAEIMEHR et al. 2010, SAGWAN et al. 2011, SinGH et al. 2011). RAMESH et al. (2009) explained the increased synthesis of phenols in natural conditions as a defensive reaction to environmental stress.

The higher content of total phenols in in vivo grown plants than in those from ex vitro adapted plants could be explained by the different altitudes at which they were grown, respectively Central Rhodopes - Beglica 1500 m a.s.l. and greenhouse, Sofia region $553 \mathrm{~m}$ a.s.l. The positive correlation between altitude and the content of caffeic acid derivatives in A. montana cv Arbo flower heads was reported (SPITALER et al. 2006, 2008). Higher levels of flavonoids in the extracts of flower heads of ex vitro and in vivo grown plants were observed compared to corresponding leaf extracts. This result is in agreement with other studies reporting flavonoid concentration in different plant parts (SAVICKIENE et al. 2002, TOMCZYK and Gudes 2003, KHATIwORA et al. 2010)

The extracts of ex vitro and in vivo samples had a radical scavenging activity greater than that of the extracts from in vitro samples. Higher activity of the extracts of these samples corresponds to a high content of phenols in them. A positive correlation between total phenolic contents and antioxidant activity has been reported by many authors (CAI et al. 2004, ShAn et al. 2005, Wong et al. 2006, Wu et al. 2006, MoldovAn et al. 2011, MAizurA et al. 2011). Moreover, the results presented confirm earlier observations that the antioxidant activity of extracts is correlated more strongly with the content of phenolics than that of flavonoids (MiliausKasA et al. 2004, NićIfOROVić et al. 2010, NiKOlOVA 2011). To the best of our knowledge the present study is the first report of polyphenol content and free radical scavenging activity of in vitro grown plants of Arnica montana. 
In conclusion, four surface flavonoid aglycones were identified in the acetone exudates of the studied samples of A. montana. No differences were observed in the synthesis of surface flavonoids among the extracts of in vitro, ex vitro and in vivo samples. But there was a difference between different organs - the extracts of the flower heads were richer in surface flavonoids than leaf extracts.

The antioxidant capacity and total flavonoid and phenolic content of the studied samples increased in the order in vitro, ex vitro and in vivo grown plants of $A$. montana. The extracts of flower heads were the richest in total flavonoids, but leaf extracts had the highest content of phenols and exhibited the highest free radical scavenging activity. A. montana plants obtained by in vitro technique and grown under natural conditions could be an appropriate source of antioxidants. The selection of highly productive lines as well as the optimization of cultivation environments is a prerequisite for the application of this system.

\section{Acknowledgements}

The authors are grateful for the financial support provided by the Bulgarian National Science Fund, Ministry of Education, Youth and Science (Project DTK-02/38). Also the authors thank Prof. E. Wollenweber for the kind gift of the flavonoid standards.

\section{References}

Assyov, B., Petrova, A., 2006: Conspectus of the Bulgarian vascular flora (in Bulgarian). Bulgarian Biodiversity Foundation, Sofia.

Burda, S., OleszeK, W., 2001: Antioxidant and antiradical activities of flavonoids. Journal of Agricultural and Food Chemistry 49, 2774-2779.

CAI, Y., LuO, Q., Sun, M., CoRKe, H., 2004: Antioxidant activity and phenolic compounds of 112 Chinese medicinal plants associated with anticancer. Life Sciences 74, 2157-2184.

Choi, C. W., Kim, S. C., Hwang, S. S., Choi, B. K., Ahn, H. J., Lee, M. Y., Park, S. H., Kim, S. K., 2002: Antioxidant activity and free radical scavenging capacity between Korean medicinal plants and flavonoids by assay-guided comparison. Plant Science 163, 11611168.

Gan, R. Y., Xu, X. R., Song, F. L., KuAnG, L., Li, H. B., 2010: Antioxidant activity and total phenolic content of medicinal plants associated with prevention and treatment of cardiovascular and cerebrovascular diseases. Journal of Medicinal Plants Research, 4, 24382444.

Gawlik-Dziki, U., Swieca, M., Sugier, D., Cichocka, J., 2011: Comparison of in vitro lipoxygenase, xanthine oxidase inhibitory and antioxidant activity of Arnica montana and Arnica chamissonis tinctures. Acta Scientiarum Polonorum-Hortorum Cultus 10, $15-27$.

Giorgi, A., Mingozzi, M., Madeo, M., Speranza, G., Cocucci, M., 2009: Effect of nitrogen starvation on the phenolic metabolism and antioxidant properties of yarrow (Achillea collina Becker ex Rchb.). Food Chemistry 114, 204-211.

Fraisse, D., Felgines, C., TeXier, O., Lamaison, J. L. 2011: Caffeoyl derivatives: major antioxidant compounds of some wild herbs of the Asteraceae family. Food and Nutrition Sciences 2, 181-192. 
HaĂRmĂnescu, M., Moisuc, A., RAdu, F., DrĂGAn, S., GERgen, I., 2008: Total polyphenols content determination in complex matrix of medicinal plants from Romania by NIR spectroscopy. Bulletin UASVM, Agriculture 65, 123-128.

HÄNSEl, R., Sticher, O., 2007: Pharmakogonosie - Phytopharmazie. Springer, Heidelberg.

Iauk, L., Lo, Bue, A. M., Milazzo, I., Rapisarda, A., Blandino, G., 2003: Antibacterial activity of medicinal plant extracts against periodontopathic bacteria. Phytotherapy Research 17, 599-604.

Khatiwora, E., Adsul, V. B., Kulkarni, M. M., Deshpandel, N. R., Kashalkar, R., V., 2010: Spectroscopic determination of total phenol and flavonoid contents of Ipomoea carnea. International Journal of ChemTech Research 2, 1698-1701.

Lyss, G., Schmidt, T. J., Merfort, I., PAHL, H. L., 1997: Helenalin, an anti-inflammatory sesquiterpene lactone from Arnica, selectively inhibits transcription factor NF-kappa-B. Biological Chemistry 378, 951-961.

Maizura, M., Aminah, A., Wan AidA, W. M., 2011: Total phenolic content and antioxidant activity of kesum (Polygonum minus), ginger (Zingiber officinale) and turmeric (Curcuma longa) extract. International Food Research Journal 18, 529-534.

Miliauskasa, G., Venskutonisa, P. R., van Beek, T. A., 2004: Screening of radical scavenging activity of some medicinal and aromatic plant extracts. Food Chemistry 85, 231-237.

Moldovan, L., Gaspar, A., Toma, L., Craciunescu, O., Saviuc, C., 2011: Comparison of polyphenolic content and antioxidant capacity of five Romanian traditional medicinal plants. Revista De Chimie 62, 299-303.

Murashige, T., Skoog, F., 1962: A revised medium for rapid growth and bioassays with tobacco tissue cultures. Physiologya Plantarum 15, 473-497.

Nićiforović, N., Mihailović, V., Masković, P., Solujić, S., Stojković, A., Muratspahić, D. P., 2010: Antioxidant activity of selected plant species; potential new sources of natural antioxidants. Food and Chemical Toxicology 48, 3125-30.

NiKolova, M., 2011: Screening of radical scavenging activity and polyphenol content of Bulgarian plant species. Pharmacognosy Research 3, 256-259.

RAMESh, J., Anshul, S., JAT, B. L., 2009: Analysis of antioxidant activity in extracts of Calotropis procera (Ait.) R.Br. Journal of Applied Biosciences 17, 899-903.

RAMACHANDRARAO, S., RAVISHANKAR, G. A., 2002: Plant tissue cultures; chemical factories of secondary metabolites. Biotechnology Advances 20, 101-153.

Rocha-Guzman, N. E., Herzog, A., Gonzalez-laredo, R. F., Ibarra-Perez, F. J., ZamBRANO-Galvan, G., Gallegos-Infante, J. A., 2007: Antioxidant and antimutagenic activity of phenolic compounds in three different colour groups of common bean cultivars (Phaseolus vulgaris). Food Chemistry 103, 521-527.

TOMCZYK, M., GudEJ, J., 2003: Quantitative analysis of flavonoids in the flowers and leaves of Ficaria verna Huds. Zeitschrift für Naturforschung 58c, 762-764.

Sagwan, S., RAO, D. V., Sharma, R. A., 2011: In-vitro and In-vivo antioxidant activity and total phenolic content of Pongamia pinnata (L.) Pierre: an important medicinal plant. International Journal of Biotechnology 4, 568-574. 
Santos, M. D., Almeida, M. C., Lopes, N. P., De Souza, G. E., 2006: Evaluation of the anti-inflammatory, analgesic and antipyretic activities of the natural polyphenol chlorogenic acid. Biological and Pharmaceutical Bulletin 29, 2236-2240.

Savickiene, N., Dagilyte, A., Barsteigiene, Z., KaZlauskas, S., Vaiciûniene, J., 2002: Analysis of flavonoids in the flowers and leaves of Monarda didyma L (in Lithuanian). Medicina (Kaunas) 11, 1119-22.

Singh, S., TANwer B. S., Khan, M., 2011: Iin vivo and in vitro comparative study of primary metabolites of Commiphora wightii (Arnott.) Bhandari.International Journal of Applied Biology and Pharmaceutical Technology 2, 162-166.

Shan, B., CAI, Y. Z., Sun, M., CORKe, H., 2005. Antioxidant capacity of 26 spice extracts and characterization of their phenolic constituents. Journal of the Agricultural and Food Chemistry 53, 7749-7759.

Spitaler, R. P., Schlorhaufer, D., Ellmerer, E. P., Merfort, I., Bortenschlager, S., STUPPNER, H., ZIDORN, CH., 2006: Altitudinal variation of secondary metabolite profiles in flowering heads of Arnica montana cv. ARBO. Phytochemistry 67, 409-417.

SPitAler, R., Winkler, I., Lins, S., YANAR, H., StupPer, H., Zidorn, C., 2008: Altitudinal variation of phenolic contents in flowering heads of Arnica montana cv. Arbo: a 3-year comparison. Journal of Chemical Ecology 34, 369-375.

Stanly, CH., Bhatt, A., Daffaralah, Ali, H. M., Keng, Ch. L., Lim, B. P., 2011: Evaluation of free radical scavenging activity and total phenolic content in the petiole-derived callus cultures of Zingiber zerumbet Smith. Journal of Medicinal Plants Research 5, 2210-2217.

Stanojević, L., Stanković, M., Nikolić, V., Nikolić, L., Ristić, D., ČAnadanovic-BruNET, J., TumBAS, V., 2009: Antioxidant activity and total phenolic and flavonoid contents of Hieracium pilosella L. extracts. Sensors 9, 5702-5714.

Williams, Ch. A., Harborne, J. B., Geiger, H., Robin, J., Hoult, S., 1999: The Favonoids of Tanacetum parthenium and T. vulgare and their anti-infammatory properties. Phytochemistry 51, 417-423.

Willuhn, G., 1991: Arnica montana L. portrait of a medicinal plant. Arnica montana L. Pharmazeutische Zeitung 136, 2453-2468.

Woerdenbag, H. J., Merfort, I., Passreiter, C. M., Schmidt, T. J., Willuhng, W., Pras, N., KAMPINGA, H., Konings, A., 1994: Cytotoxicity of flavonoids and sesquiterpene lactones from Arnica species against the GLC-4 and the COLO 320 cell lines. Planta Medica 60, 434-437.

Wong, C., Li, H., CHEnG, K., CHEN, F., 2006: A systematic survey of antioxidant activity of 30 Chinese medicinal plants using the ferric reducing antioxidant power assay. Food Chemistry 97, 705-711.

Wu, C. Q., Chen, F., Wang, X., Kim, H. J., He, G. Q., Haley-Zitlin, V., Huang, G., 2006: Antioxidant constituents in feverfew (Tanacetum parthenium) extract and their chromatographic quantification. Food Chemistry 96, 220-227. 